\title{
O Livre Acesso à Injustiça
}

\section{Raimundo Nonato Chaves Neto}





\section{O Livre Acesso à Injustiça}

\section{COS INTRODUÇÃO}

Constitui o presente trabalho uma explanação crítica a respeito do acesso à justiça, tomando-se como base a sua repercussão dentro da realidade brasileira e as conseqüências no âmbito das relações sociais desta mesma sociedade, sem desprezar, logicamente, a situação mundial.

Os estudos de sociologia do direito, intensificados durante o período em que fui monitor do notável professor Dr. Agerson Tabosa, despertaram em mim uma curiosidade, esteirada por uma grande preocupação, a respeito dos fenômenos sociais, principalmente os decorrentes da desigualdade social. Tais desigualdades podem ter diversas variantes: econômicas, políticas, sociais, culturais, regionais, etárias, mentais, raciais etc.

Nas lições de Mauro Cappelletti há uma tentativa de definir o que vem a ser o acesso à justiça, chamando a nossa atenção para as finalidades primordiais do sistema jurídico. Em primeiro lugar, a justiça deve ser acessível a todos, constituindo-se esta como finalidade principal; em segundo lugar: as decisões ou sentenças proferidas devem estar de acordo com a idéia universal de justiça, produzindo efeitos benéficos e socialmente justos. A ausência da justiça social compromete a função estatal.

O acesso à justiça civil e à proteção judiciária, em geral, exclui, na prática, as classes sociais que não tenham recursos materiais suficientes para defender seus interesses (Lopes, 1997, p. 134), ou seja, freqüentemente perde-se um direito líquido e certo pelo fato de não poder pleiteá-lo, às vezes por falta de representatividade jurídica, outras por dificuldade de transporte ou até mesmo por total ignorância de ser titular desse direito. 
A dificuldade do acesso à justiça enfrentado pela classe pobre restringe-se à titularidade de direitos, mas quando tratamos das obrigações, só neste momento encontramos uma igualdade formal dos revolucionários franceses. Porém como falarmos em tratar igualmente os desiguais? A ironia proferida pelo francês Anatole France no século XIX “é igualmente proibido aos ricos e aos pobres dormir sob as pontes”, ressalta a questão da desproporcionalidade na aplicação da lei, pois como querer que alguém que receba apenas dois salários-mínimos seja apenado com a mesma multa que outro indivíduo que receba quarenta vezes este valor. O nosso Estado de Direito deve buscar a eqüidade.

A lei deve procurar satisfazer a todos que anseiam por ela, não se restringindo apenas a dar a cada um que é seu, mas dá-lo de maneira justa e dentro de uma adequação e finalidade social.

\section{@ NoÇões de AcEsso À JustiÇA}

A palavra justiça não pode ser encarada ou interpretada, simplesmente, como a prestação judiciária, portanto torna-se notório que não basta a possibilidade do acesso à justiça, “é necessário que também se viabilize o acesso à ordem jurídica justa”, como afirma Watanabe. A efetividade é imprescindível à ordem jurídica justa.

O acesso à justiça é o mais importante princípio constitucional, segundo Lindberg Batista, pois é o norteador de diversos princípios (devido processo legal, direito de ação e de defesa, além de outros). Vejamos o que nos diz a Constituição de 1988 no seu artigo 5º inciso XXXV, conhecido como Princípio da Inafastabilidade de Jurisdição, ou Princípio do Controle Jurisdicional: “A lei não excluirá da apreciação do Poder Judiciário lesão ou ameaça a direito”. O Estado, portanto, deverá comandar e ditar as regras para que o devido processo legal e outras garantias constitucionais sejam assegurados nos casos concretos, prestando uma proteção efetiva dos direitos individuais, difusos e coletivos.

Mauro Cappelletti e Bryant Garth (“Acesso à Justiça”, ed. bras.1988), comentam e nos fazem lembrar que, nos estados liberais do Século XIX, era comum e, perfeitamente aceitável pelo poder público, a idéia do cidadão pobre não ter condições financeiras para propor ação, ou, "utilizar plenamente a justiça”. Esta idéia dos estados liberais à luz do “laissez-faire” apregoava 
ainda que a justiça só podia ser acionada e proteger àqueles que pudessem custeá-la, caso contrário o indivíduo estava à mercê de sua própria sorte e deveria buscar, sozinho, resolver o seu conflito ou garantir o seu direito.

O simples acesso aos tribunais não pode ser considerado como acesso à justiça, pois este requer para si o reconhecimento de ser um direito fundamental formal e não apenas a estrita e reduzida conceitual daquele de menor alcance.

“O exercício da cidadania, nos tempos de hoje, exige e pressupõe amplo acesso à justiça”, conforme matéria da Agência Senado em 06/12/2003. Objetivando-se este amplo acesso criou-se, na Constituição de 88, a obrigatoriedade do Estado em prestar, gratuitamente, assistência jurídica de forma integral a todas aquelas pessoas carentes e desprovidas dos recursos necessários para pagamento de advogados ou de custas processuais, procurando, assim, garantir a isonomia no acesso à justiça.

\section{Causas que Dificultam o Acesso à Justiça}

O princípio da via judiciária está assegurado por todas as Constituições brasileiras, não sendo caracterizado apenas pela gratuidade, mas vale ressaltar que, principalmente, pela garantia universal de todo e qualquer direito, independentemente de ser contra particular ou contra poder público, desvinculando-se ainda, das capacidades econômicas de cada um. A abertura da via judiciária é, segundo Canotilho e J. Nalini, um direito fundamental formal, além de ser auto-aplicável.

As normas constitucionais buscam assegurar, de modo impessoal, a proteção às pessoas, punindo também àquelas que tiverem um comportamento indevido. As pesquisas sociológicas demonstram, no entanto que, há uma forte seletividade na aplicação dessas normas legais, acontecendo, na maioria das vezes, uma repressão e um controle maior aos grupos sociais menos favorecidos (Sabadell, 2000, p. 141).

Recente estudo realizado pelo Centro de Estudos Judiciários do Conselho da Justiça Federal, cujo título proposto foi "a opinião da sociedade civil organizada a respeito da Justiça Federal”, recolheu dados a respeito da imagem que a sociedade tem acerca do Poder Judiciário (tido comumente como sinônimo de justiça). O resultado demonstrou uma grande insatisfação social, além da grande negatividade com que se vê a Justiça Federal, atingindo 
um nível alto de rejeição (56,9\%), contra 28,7\% de respostas positivas e mais 14,4\% que afirmaram não saber. Além disso, 79,2\% da sociedade civil considerou a Justiça Federal como elitista, e, 83,3\% ressaltaram a morosidade da Justiça Federal, tendo como defensores da agilidade apenas dez por cento deste último número.

O acesso à justiça traz consigo uma série de barreiras e impedimentos que obstam o seu livre exercício (Rehbinder, 2000, pp. 176 e ss.):

- barreiras econômicas (altos custos processuais).

- barreiras sociais (medo de romper relações sociais).

- barreiras pessoais (dificuldades culturais e de comunicação).

- barreiras jurídicas (excessiva duração do processo).

Vale ressaltar que estes problemas não são exclusivamente brasileiros. Comentaremos cada um dos itens acima mencionados, individualmente, para que se tenha uma dimensão aproximada deste grande problema. Vejamos, a seguir cada obstáculo:

\subsection{BARREIRAS ECONÔMICAS}

A erradicação da pobreza e da marginalização encontrou abrigo como objetivo político-jurídico na Constituição Federal de 1988 (art. $3^{\circ}$, inciso III), assegurando, junto a outros dispositivos legais, direitos sociais às camadas inferiores da escala social.

O surgimento do direito trabalhista ao longo do século XX, foi uma forma de reconhecimento da desigualdade de condições que são estabelecidas entre patrão e empregado, sendo este mais fraco e necessitando da tutela do Estado. O Código do Consumidor, O Estatuto da Criança e do Adolescente, O Estatuto do Idoso e o Estatuto da Mulher Casada representam tentativas de tornar menos negligente o tratamento dado aos menos favorecidos.

Os interesses das classes dominantes, todavia, prevalecem sobre os das classes menos favorecidas (dominadas), pois o princípio socialista “dar de acordo com as capacidades e receber de acordo com as necessidades" não é interessante para quem tem assegurado o direito de propriedade. O que se vê claramente é a eternização da desigualdade social, como ressalta Ana Lúcia Sabadell (Manual de Sociologia Jurídica). 
A barreira econômica é a principal causa que dificulta o acesso à justiça, pois mesmo com a grande evolução que se deu na sociedade, mudanças ocorreram apenas no campo do “ter”, mas não no do "ser”, ou seja, vale o dito popular "cada um vale o que tem”. Em geral para o pobre resta apenas o controle social exercido pelo Estado.

A gratuidade das custas processuais não é suficiente, pois se torna ainda necessária a constituição de um advogado. A prestação de serviços de um advogado gratuito traz alguns inconvenientes, pois, com raríssimas exceções e não sejamos hipócritas de negar, há uma distância muito grande entre o serviço prestado a alguém que contrata e a um "despossuído qualquer” que não tem como, sequer, locomover-se.

Cerca de $40 \%$ da população brasileira vive em estado tido tecnicamente como de miséria, segundo dados da Unesco. O pior é que este fenômeno mundial tende a crescer ainda mais, revelando-se um grande problema que teremos que enfrentar desde agora, o início do terceiro milênio, pois a miséria é uma porta para a desigualdade social.

Facilmente os problemas do pobre são resolvidos nas delegacias, bastando para isso que ele figure como suspeito, pois, rapidamente, ele é recolhido a uma cela lotada de outros presos, geralmente autores de crimes semelhantes e de menor potencial ofensivo: embriaguez, desordem, roubo de galinhas, botijões de gás, etc. Este fenômeno pode ser batizado por “O livre acesso à injustiça”, pois facilmente o indivíduo de poucos recursos financeiros tem acesso ao sistema penitenciário, enquanto são cometidos crimes absurdos pelos poderosos e não punidos pelas autoridades competentes.

\subsection{BARREIRAS SOCIAIS}

A falta de confiança no aparelho estatal responsável pela realização da justiça impede, freqüentemente, que cidadãos, independentemente da condição financeira, procurem a justiça. Sabadell comenta recente pesquisa, em que foi constatado que $67 \%$ das pessoas não procuram a justiça do trabalho para resolver conflitos trabalhistas, optando por resolver sozinhos, atribuindo, assim, aos órgãos responsáveis uma credibilidade duvidosa. Essa incredibilidade é fruto de diversos fatores, 
dentre eles está a experiência malograda anteriormente em outro processo e, até mesmo o comentário que se ouve entre familiares e amigos a respeito da “inutilidade de uma ação que de nada adiantará”. Porém, por muitas vezes, essas barreiras são erguidas pelo simples preconceito de que o poder público não cuida dos seus cidadãos, tornando-se, assim, um círculo vicioso.

A sociedade, de maneira geral, encara com muita desconfiança todas as agências de controle, portanto a segurança pública não estaria excluída desse grupo. Em conseqüência dessa falta de confiança, por diversas vezes, cidadãos feridos ou ameaçados em seus direitos não buscam o poder estatal para resolução destes problemas, pois temem vingança, rompimento de importantes relações sociais com patrões, vizinhos e até amigos.

\subsection{BARREIRAS PESSOAIS}

A educação pública do país atravessa um período de estagnação, restringindo-se apenas aos que têm condições de prover os estudos dos filhos em colégio particulares. A rede privada tornou-se, portanto, a única opção válida para garantir o acesso às universidades. $\mathrm{O}$ direito à informação é “igual” para todos, porém torna-se irônico falar em igualdade de condições quando na verdade o jovem pobre que trabalha desde criança não tem a mesma condição de tempo, tampouco de equipamentos para ter acesso à informação.

O que podemos perceber, notoriamente, é que a falta de informação gera cidadãos ignorantes dos seus próprios direitos e deveres, ocasionando, conseqüentemente, indivíduos excluídos do acesso à justiça. Ainda há os casos em que, apesar de pleiteado seu direito junto a advogados ou até mesmo juízes, a inferioridade cultural acaba por dificultar as relações jurídicas que, naturalmente, exigem linguagem apropriada. Esta dupla seletividade estabelece com a desigualdade social uma relação de criador e criatura.

\subsection{BARREIRAS JURÍDICAS}

A maior parte dos conflitos ocorridos na sociedade são resolvidos pelos próprios protagonistas, porém uma grande parte deles é encaminhada ao Poder Judiciário, que, obrigatoriamente deve dar uma solução. Porém há vários problemas que rondam o Judiciário, talvez oriundos até do tipo de sociedade que se tem, já que ambos são espelhos um do outro. 
A duração prolongada dos processos, o formalismo exagerado, as dispendiosas custas, honorários de advogados, além de outros fatores que se configuram em verdadeiras "tramelas" a trancar as portas da justiça para o cidadão comum, como afirma Roberto P. Bacellar; acabam por criar um grande empecilho ao perfeito funcionamento e realização da justiça.

O que vemos, constantemente, é o desespero de aposentados à beira da morte e que não têm esperança de “descansar em paz” e vendo o problema jurídico já solucionado. Na verdade, a morosidade tem a ver com a quantidade de processos que se avolumam nas prateleiras do judiciário e todos são frutos da burocracia.

A lentidão na prestação jurisdicional não é problema exclusivo dos brasileiros, segundo Sidnei Beneti, esta é uma realidade de diversos países. Não podemos, no entanto, nos espelharmos em quem está fazendo errado, devemos trabalhar para que possamos fazer a coisa certa, já que a morosidade da Justiça configura-se como uma injustiça. Há pessoas que esperam por uma decisão judicial para poderem colocar os filhos dentro de uma casa e sentirem-se seguras e protegidas, no entanto a prestação jurisdicional do Estado segue obedecendo à letra fria da lei. O problema, todavia, não é ocasionado apenas pelo juiz, que é o agente político responsável, há o grave problema da burocracia, relacionado anteriormente, contaminando todos os setores da justiça. Até mesmo a nova Lei dos Juizados Especiais já foi maculada pelo sistema burocrata antigo, quando na verdade o que se precisa é criar um novo sistema, mais eficaz e rápido para o atendimento à sociedade, dando assim uma cara nova para uma lei nova. Esta tarefa não parece ser realizada com facilidade, porém, inicialmente, é necessário que se faça a conscientização de funcionários da justiça e juízes, objetivando uma distribuição eficaz da justiça.

Indubitavelmente, no Brasil, o estilo de vida dos abastados não se apóia no altruísmo. Progressivamente o que se vê é um completo "cada um por si e que se quebre o mais fraco”. Os sujeitos da classe pobre ou miserável não conseguem exercer a sua cidadania, sendo identificados apenas quando cometem algum crime e têm o nome fichado na delegacia. Não há uma equivalência para estes indivíduos entre direito e dever, colocando por água abaixo a idéia de isonomia e igualdade. 
A questão da linguagem reflete a falta de sensibilidade de alguns magistrados e a inaptidão de outros em estabelecer diálogo inteligível com cidadãos comuns e de pouca cultura. A linguagem jurídica é incompatível com o nível instrucional da maioria dos brasileiros. Vejamos o relato que nos faz Roberto Bacellar no artigo publicado em 24.08.2004:

"Negligenciam os magistrados que não procu-ram falar de maneira a serem compreendidos. Recordo-me de uma situação real ocorrida em 1989: realizava-se uma audiência possessória;

o magistrado tomou o compromisso formal da testemunha indagando, como de praxe, se a testemunha prometia dizer a verdade e se estava ciente de que se faltasse com a verdade poderia ser processada e condenada. Eram várias as testemunhas arroladas e o juiz, como já havia procedido com outras quatro ou cinco ouvidas anteriormente, passou a inquiri-la, com a praticidade que o caso recomendava:

- O Senhor João está no imóvel?

- Há quanto tempo o Senhor João está no imóvel?

A testemunha, diferentemente das outras que haviam afirmado que o Senhor João estava no imóvel há mais ou menos dois anos, já quebrou a lógica na primeira resposta: depois de jurar que iria dizer a verdade, afirmou que o Senhor João não estava no imóvel.

O juiz, ainda com bastante paciência, voltou a repetir a pergunta, lembrando a testemunha de que ela havia prestado o compromisso legal de dizer a verdade; advertiu novamente a testemunha de que se mentisse, poderia ser processada e até condenada!

Mais uma vez a testemunha confirmou estar dizendo a verdade, respondendo negativamente à pergunta do magistrado.

Foi então perquirida pela terceira vez, já agora com maior firmeza, nos seguintes moldes:

- O Senhor João não está no imóvel?

Em face da indagação negativa, a teste-munha respondeu: - Não doutor, ele está ali! - apontando para o local da sala de audiências onde o autor da ação, Senhor João, estava sentado". 
Equívocos dessa natureza ocorrem, constantemente, felizmente, neste caso, o juiz percebeu a tempo. É natural que as pessoas não se sintam à vontade numa sala de audiência, piorando ainda mais quando esta pessoa é limitada de instrução ou de estudos.

Porém, a linguagem jurídica não é responsabilidade exclusiva do juiz, sendo ela remanescente das tradições e da lei. No entanto, pode o juiz despir-se da erudição e aplicar linguagem simples no processo, pois o que se espera e se tem como principal objetivo é a solução concreta do conflito e não receber aplausos para uma impecável explanação acadêmica.

O advogado é o elemento que possibilita a defesa dos direitos, na área cível e criminal, principalmente num regime democrático.

Cheatham, em sua obra "Problemas do Advogado nos Estados Unidos”, divide em privados, públicos e mistos, os métodos para prestação jurisdicional aos pobres. Os privados são prestados por ordem de classe dos advogados, enquanto os públicos são formados pelos dativos. O sistema misto congrega os dois anteriores, sendo formado por particulares e públicos. Cappelleti e Garth enfatizam, ainda o sistema utilizado em alguns países como Alemanha, Áustria, França, Holanda e Inglaterra, que destina-se ao litigante de baixa renda, e, consiste na nomeação por parte do litigante de um patrono que gostaria de ter se pudesse pagar um advogado, então ao ser nomeado o advogado receberá os honorários pelo Estado.

O advogado, de maneira geral pode e deve contribuir para a evolução do Direito, pois mesmo que a sentença não seja por ele proferida, é ele quem pleiteia aquele direito que vai ser declarado. Além do mais, as ações dos advogados refletem-se na doutrina e na jurisprudência.

\section{Perspectiva Para o Livre Acesso À Justiça}

O povo brasileiro acompanha com uma certa desconfiança o desenrolar dos problemas incumbidos ao Estado. O que se vê é uma crescente anomia, principalmente nos morros cariocas, onde o poder paralelo dá respostas sociais que o Estado de Direito não dá. A sociedade se vê obrigada a se curvar ao comando de traficantes e agentes "extra-estatais".

O Estado sente-se coagido a promover, imediatamente, uma reforma em seus órgãos administrativos, principalmente nos de Justiça. 
A Constituição de 88, caso dependesse, exclusivamente, do tamanho que tem, seria a mais justa do mundo, pois é a maior entre as de outros países, ganhando até mesmo da Índia, se computarmos os incisos do artigo $5^{\circ}$ como artigos. O instante em que ela nasceu representou uma ruptura com o regime ditatorial, portanto ao concebê-la como “A Constituição Cidadã”, Ulisses Guimarães ressaltou o momento histórico como uma vitória da democracia restabelecida. Um dos grandes méritos da nossa última Carta Magna foi exatamente abrir novos caminhos para o amplo acesso à justiça, exigindo a criação dos Juizados Especiais, que representou na prática uma maneira de aproximar mais a Justiça e o Povo. A Emenda Constitucional 22 de 1999 tratou da criação dos juizados no âmbito da Justiça Federal.

Ao compararmos a nossa Carta com a americana, podemos fazer as seguintes comparações: a primeira é que a nossa tem apenas 16 anos enquanto aquela tem mais de 200; a segunda é que, apesar de 200 anos a Constituição americana tem apenas 27 emendas, enquanto a nossa já tem 42. Percebemos, claramente, que as falhas da Justiça são oriundas também do Executivo e do Legislativo, não podendo, portanto, ser atribuída responsabilidade exclusiva pela não realização da justiça ao Poder Judiciário, e sim, de todos os poderes.

“A busca pelo acesso à justiça”, como leciona André Macedo de Oliveira, "não se restringe às reformas processuais”. O elemento normativo não pode ser apontado como solução para essa crise do acesso, representando, na verdade, apenas um dos fatores. O Poder Judiciário tem condições de dar uma resposta mais eficaz e rápida aos anseios populares por justiça. O que mais se deseja é vislumbrar um Judiciário acessível a todos os cidadãos, de acordo com o que rege a nossa Constituição. Carlos Mário da Silva Velloso sustenta que "devemos viabilizar o acesso à ordem jurídica justa e que esta compreende, além de um direito material justo, o aperfeiçoamento da prestação jurisdicional, assentado, sobretudo, no aperfeiçoamento do ensino jurídico, e, conseqüentemente, das pessoas que vão dar vida ao direito, os magistrados, os advogados, os procuradores, os membros do Ministério Público e os demais operadores do direito”. De acordo com o Desembargador e ex-presidente da Associação dos Magistrados do Brasil, Luiz Fernando Ribeiro de Carvalho, “60\% dos processos que chegam à Justiça brasileira são absorvidos pelos juízes especiais”. Afirma, ainda, que “a demora nos processos se deve à conjugação de dois problemas: excesso de demanda e 
escassez de juízes. No Brasil, há 1 (um) juiz para 30.000 (trinta mil) habitantes, enquanto na Europa a média é de 1 (um) juiz para cada 7.000 (sete mil) pessoas. Na Alemanha, há 1 (um) juiz para cada 3.000 (três mil).

No Brasil, há alguns movimentos sendo realizados para tentar melhorar a aplicabilidade e o acesso à justiça. A criação dos Juizados Móveis; o plano para que a Justiça funcione 24 horas, como já existe no Distrito Federal; as comissões de conciliação prévia e o rito sumaríssimo, inovações da Justiça do Trabalho; o projeto dos juizados itinerantes; etc.

Importante também falarmos de conciliação, mediação e arbitragem, que são soluções polêmicas, porém prestam um serviço auxiliar ao Judiciário, à medida que desafogam as pilhas de processos. Além do mais, devemos considerar as decisões dos alternativistas, que, independentemente, do lado que esteja com a razão, sempre optam por beneficiar a parte mais fraca.

\section{Conclusão}

Ante as considerações anteriores, chega-se à evidente conclusão de que a mãe de todos os problemas brasileiros ainda é a velha idéia de que a desigualdade social é natural e inerente ao homem. Enquanto cada setor da sociedade não assumir o papel de co-responsável pelos problemas sociais não teremos acesso à justiça, acesso à saúde, acesso à educação, acesso à informação, acesso ao lazer, acesso ao trabalho, enfim, todas as portas que poderíamos abrir para que a maioria dos “despossuídos” da sociedade tivesse acesso à cidadania, geralmente fechamos e não temos a menor vontade de abrir, atribuímos a posse da chave sempre a outra pessoa.

A atual proliferação dos cursos jurídicos e a criação de inúmeras Universidades e Faculdades de Direito representam uma grande oportunidade de permitir ao Povo o acesso à justiça, podendo inclusive ser ventilada a possibilidade de criação de Juizados Especiais em tais universidades. Os estudantes de Direito necessitamos alcançar uma dimensão ético-pedagógica como operadores do direito, para que aos excluídos da sociedade seja permitido o acesso à cidadania. A atividade acadêmica deve também ter função social.A possibilidade concreta de ser tutelado pelo Estado, através do Judiciário transforma o indivíduo, politizando-o e educando-o. 


\section{Bibliografia}

BATISTA, Lindberg Leitão. Juizados Especiais Trabalhistas: Resultante do Princípio da Celeridade e do Instituto de Conciliação. Livro do IV Congresso Nacional de Direito Processual Civil, Trabalhista, Penal e Administrativo, Recife-PE, 1996.

CANOTILHO, José Joaquim Gomes. Direito Constitucional. $5^{\text {a }}$ ed. total. revista e aumentada, Coimbra, Almedina, 1992.

CAVALIERI FILHO, Sérgio. Programa de Sociologia Jurídica. São Paulo, Forense, 1998.

GRECO FILHO, Vicente. Tutela Constitucional da Liberdade. São Paulo, Saraiva, 1989.

RODRIGUES, Horácio Wanderley. Acesso à Justiça no Direito Processual Brasileiro. São Paulo, Acadêmica, 1994.

SABADELL, Ana Lúcia. Manual de Sociologia Jurídica. São Paulo, Editora Revista dos Tribunais, 2000. 